\title{
Redefining Professional Development in Romanian Technical Higher Education
}

\author{
Brânduşa Prepeliţă Răileanu \\ University - Politehnica" of Bucharest \\ Faculty of Engineering in Foreign Languages \\ Splaiul Independenţei 313, Ro-060032 \\ Bucharest, Romania
}

\begin{abstract}
Using examples from the educational activity developed in the Polytechnic University of Bucharest, the paper presents the student participation mechanisms and structures at academic level that offer real opportunities in learning and teaching. It also describes the academic transformation towards a democratic learning environment, with a participative management, flexible curriculum offers, and a modern, democratic organizational culture. Discussing the fact that the introducing of ICT in education is a significant investment for the future, the paper shows the impact of the instructional strategies assisted by computer on the achievement of learning objectives.
\end{abstract}

Keywords — policies for education, set of qualifications, institutional goals, interdisciplinary cooperation, assessment, educational needs, performance, efficiency, mathematical disciplines, digital age.

\section{INTRODUCTION}

Reviews of Romanian policies for education are most prominent among a range of activities that lead to analyses of education policy development and implementation in response to or anticipation of wider economic and social trends and developments. There is involvement of Ministries as well as professional groups, researchers and others, in formulating and carrying out the work and in discussing the findings. The aim is to improve the understanding of issues, implications for education policies and experience with the range of national policy options and strategies [2].

The reform of education, training and human resource development is an integral part of the transition to a democratic society and market economy. Romania has made progress in all these areas since reform began in 1990. The challenge has been to promote and support changes that meet the needs of the new economy and society as well as the interests of all young people and adults, in the face of a shortage of financial and human resources. The rapid expansion of higher education and its growing cost are focusing attention in many European countries on issues of quality, relevance and efficiency.

\section{THE INCREASE OF THE GRADUATES'VERSATILITY AND EMPLOYABILITY}

Universities are facing the task of better educating their undergraduate and graduate students by restructuring their curricula to increase the versatility and employability of the graduates. All disciplines have been targets, however, considerable importance is placed on graduates in the natural sciences, engineering, health sciences, computer sciences, and other quantitatively-based fields.

One challenge facing research institutions is that of finding a balance between the basic academic activities of teaching and research. Within the scientific and engineering disciplines, attempting to find the flexibility to blend the priorities of teaching and research has been a perennial problem. The standing of an institution is in direct relationship to the research productivity of its faculty, and the competition for grants and scholars has led many research institutions to place increased emphasis on research at the expense of teaching. In many research institutions, research productivity has been given more weight than teaching effectiveness when deciding tenure or promotion. Efforts are underway at some institutions to change the reward system and evaluation of their faculty members.

From an overall point of view it is the object of the education system to qualify the individual human being for working life and for life in general. Thus, it is not solely the aim of the education system to qualify young people and adults to acquire and reproduce the knowledge, which is disseminated by their teacher. The crucial new factor in connection with the information society is that young people and adults are to be qualified creatively to sort, select, process and use the great amount of information, which ICT gives access to. Moreover, in connection with the basic education they are to acquire new methods of learning processes in order to enable them to take a material responsibility for a continual and lifelong updating of their qualifications. 
The quality of the teaching and research staff can be measured by the proportion of teachers to students. In the graph below the evolution of this value in the last academic years is described.

It follows that the University Politehnica of Bucharest, together with the other prestigious technical universities in
Romania (the University Politehnica of Timisoara, the Technical University of Cluj-Napoca, the Technical University of Iassy) has this value with approximately $50 \%$ bigger than the national average. Taking into consideration the results of the scientific research from these universities, the result is a higher efficiency in the technical higher education.

The quality of the teaching and research staff can be measured by the proportion of teachers to students.

In the graph below the evolution of this value in the last academic years is described.

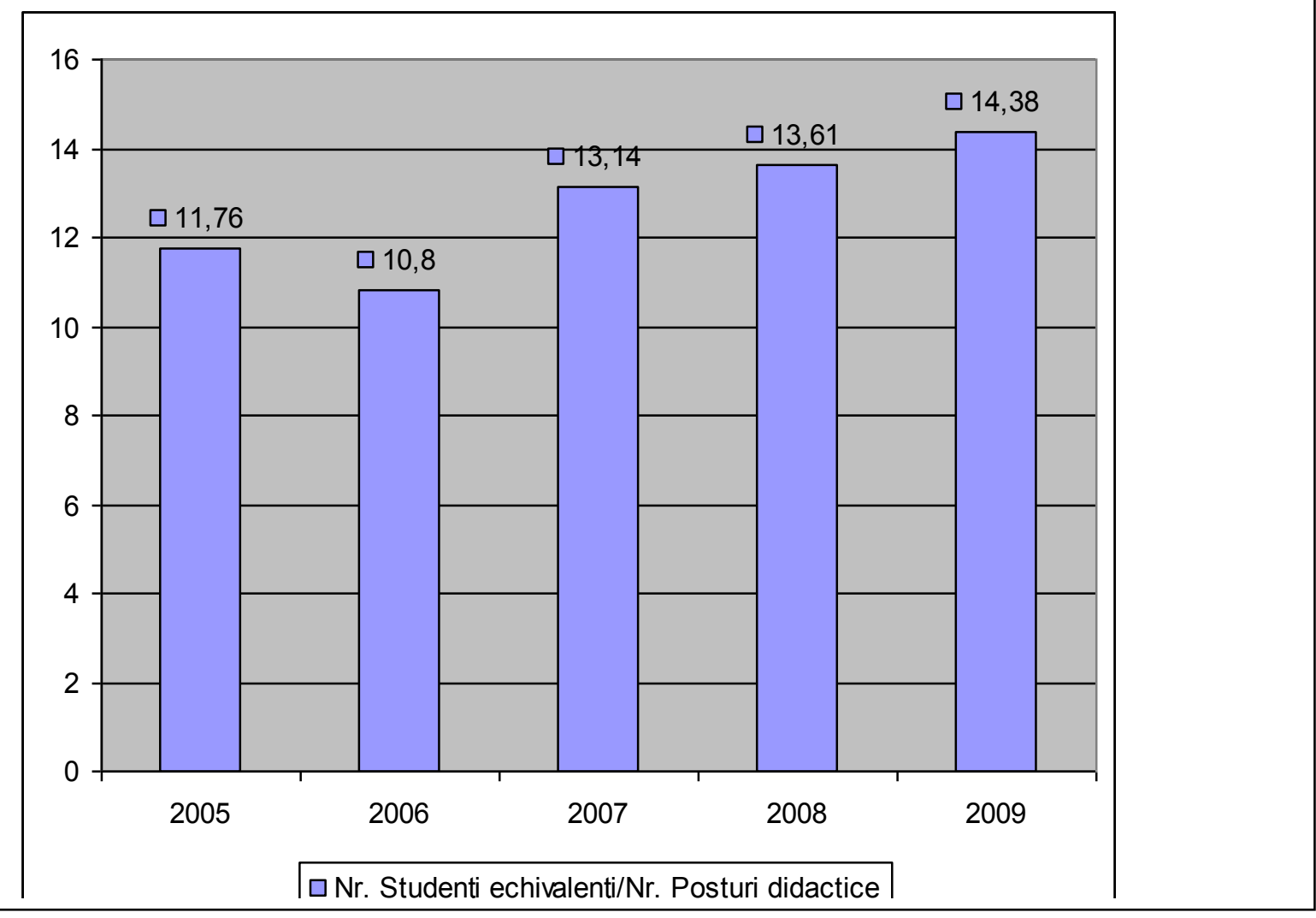

How should universities balance their role of serving an evolving on-site student demographic and exploring new, potentially for-profit models of online education? They must first assume that future campus populations will represent a mix of residential and off-site students who will expect an innovative blend of ICTs in their courses. And they should continue to experiment, because university experimentation and assessment will be an essential contributor to our knowledge about what does not work in online distributed education. Along the same line of thought, university experiments should:

- $\quad$ Be developed within the context of the residential university

- $\quad$ Facilitate the production of high-quality software and infrastructure that enhance teaching

- Monitor the quality of learning more closely

- Test whether online education can substitute for classroom experience

- Test what sources of revenue can cover the costs of both experimentation and scaling.
University leadership should be very clear about institutional goals and possible market niches when planning to serve off-site students. There are a number of key issues to consider when thinking about the costs and benefits of entering into the expensive and fast-changing world of online residential and off-site distance education. We are all aware of the emergence in the past few years of a diverse array of online education models. Choices that make sense for an extension arm of a research university or a well-focused proprietary institution may be entirely different from choices that are realistic for a community college or a small residential institution.

The education system also has to take into account the socalled less advantaged groups of students, which for various reasons run the risk of becoming marginalised in the usual education system [Livingstone, 1999]. It is therefore necessary to initiate ICT-based projects with the aim of developing new methods and teaching materials, which can support the learning processes of these groups [1]. They can be focused on individualized teaching programs with a starting point in the 
specific needs of the individual student. In cooperation with other agents in the educational field, areas of special priority could be:

- Access to inexpensive and rapid network connections from the educational institutions as well as from the distance workplace.

- Development of and access to a comprehensive supply of quality services for educational purposes via network.

- Continual development of ICT-based teaching programs and materials, which can generally support the learning processes on all levels, including especially the learning processes of the so-called less advantaged group of students.

University planners must consider that significant questions remain about whether high-quality interactions between student and teacher, and among students - the sine qua non of a quality educational experience-can be replicated, or even approached, in online environments. If one spends any time around computer scientists at a research university, however, one realizes that, indeed, Internet and the applications it can support will provide ubiquitous highquality online interactions among individuals in the not-toodistant future.

New models for initial training have already started to be tested as experiments: classroom management, integrated education, multicultural education etc. These will consolidate the training programs providing them with a high professional effectiveness.

The emergency of new and promising premises for teacher education development has also been proved. First of all new professional roles have to be associated to the teaching career:

- To get acquainted with students' characteristics and to offer psycho-pedagogical counselling on this basis;

- To adopt a new approach on/upon design, management and evaluation of learning activities;

- To offer educational services adequate to community's request;

- To participate to educational process innovation;

- To have good knowledge and understanding of students specific needs;

- To acquire special skills for a better communication with students or with other social partners involved in the educational process;

- To accept being introduced in the process of professional self-development and lifelong learning.

In order to foster such an interdisciplinary cooperation, it has been necessary that the curricula and the plans of study should be mapped out by the national departmental commissions which are coordinated by the National Council for the Curriculum (NCC).

NCC has made the curricula; it has ensured their vertical and horizontal coherence and has submitted them to the Ministry of Education for approval.
The process of revising the curricula, of consultations and of approval comprises a sequence of stages, as such:

- the selection of the model of curriculum following the consulting of experts;

- the revising of the curriculum drafts by the national departmental commissions and their forwarding, accompanied by a report, to the Commission of Experts of the National Council for the Curriculum;

- the consulting of those interested in the curriculum drafts;

- the centralization of the suggestions made during the consultations, a process carried out by the members of the Commissions for coordination of the NCC (these are commissions that coordinate the activity of the national departmental commissions by regrouping them on curricular areas);

- the communication of these suggestions to the commission of experts (CE) of the NCC.

- the discussing of possible changes to be brought to the curricula from the perspective of the suggestions that have been made and the analysis of the vertical and horizontal correlations;

- the sanctioning of the appropriate curricula by the executive board of the NCC

- the drafting of the sanctioning documents and the sanctioning of the curricula by Order of Minister

The National Curriculum includes the reference points, the criteria and the principles underlying the revising of the new curricula. These are as follows:

- the reference to the dynamics and current necessities as well as to the projected aims of the Romanian educational system, which are generated by the evolution of society and are specified in official documents of educational policy.

- the reference to the current tendencies and the generally accepted international criteria in the domain of curricular reforms.

- the reference to those traditions of the Romanian educational system that are relevant from the point of view of the ongoing reform.

In this context, the principles regarding the curriculum as a whole are important:

- The curriculum must reflect the educational level of the Romanian technical high school as defined by the Education Act.

- The curriculum must reflect the dynamics of the social and cultural values that are characteristic for an open and democratic society.

- The curriculum must stimulate the development of critical and creative thinking.

- The curriculum must help the students discover their gifts and make the best of them to their own benefit and that of the whole society. 


\section{A PROJECT TO ADAPT THE STUDY PROGRAMS TO THE LABOR MARKET}

Educational work is a key element for both human capital formation and the promotion of democratic values. Therefore it has been identified as one of the priorities of the project launched by the Ministry of Education regarding the project entitled The Training of University Teachers and Students in the Field of Using Modern Tools to Teach-LearnAssess for the Mathematical Subjects in Order to Acquire Important Professional and Practical Skills for the Labour Market.

Funded by the European Social Fund, the project aimed to adapt the study programs of mathematical disciplines to the labor market demands and the creation of mechanisms and tools to extend learning opportunities.

The project covered a period of 36 months contributing directly to the general objective of Sector Operational Program of Human Resources Development POSDRU and entered in the field of intervention 1.2 Quality in higher education. The project was implemented by the Ministry of Education, Research and Innovation in collaboration with The Red Point, Agency OSC, Polytechnic University of Bucharest, University of Bucharest, University of Civil Engineering of Bucharest, University of Pitesti, Technical University Gheorghe Asachi of Iassy, West University of Timisoara, University of Galati, Technical University of Cluj-Napoca and University of Alba-Iulia.

Each of the universities participating in this project have created one training center for teachers and students involved in increasing the quality of Mathematical education in Romania and in developing best practice on national and international level.

The specific objectives of the project were:

- Assessment of educational needs, of teachers' and students' aims related to the use of mathematics in higher education, masters and doctorates;

- Analysis the effectiveness and relevance of current curricula at the level of performance and efficiency, to develop knowledge and skills for students who studied mathematical subjects at university;

- Development and harmonization of university curricula of mathematical disciplines, according to the demands of the labor market;

- Develop and implement a training program for teachers and students interested in partner universities based on the development and harmonization of curricula;

- Creation of 9 training centres for teachers and students involved in increasing the quality of mathematical education in Romania and in developing best practice on national and international level;

- Create a resource base of innovative, modern and functional teach-learn-assess for the mathematical subjects in universities;

- Develop a portal online as a source of teaching resources for teachers and students who wish to improve their knowledge in the field of Mathematics, as well as a modern and flexible instrument of communication, learning and assessment;

- Fostering cooperation and communication between students;

- Using new knowledge and skills in the labor market.

In these conditions, the project we refer aims to achieve a high European level in learning - teaching mathematics. Here are some of this project activities:

- Developing awareness of the need to harmonize the activities of the curricula for mathematics and related disciplines in the context inter/multidisciplinary;

- the implementation of the harmonization of curricula at the partner universities in the project;

- Identifying opportunities in the labor market that require mathematical applications;

- Creating the infrastructure of centres;

- Developing teaching-learning-assessing resources;

- Develop a portal that allows the support of the communication strategy,

- Facilitate the creation of innovative resources and dissemination of innovative electronic resources;

- Carrying out practical placements in the labor market

\section{THE EXTENDED ROLE OF THE TEACHER}

The teachers are to be educated concurrently with the increase in the use of ICT. New knowledge based on the latest research and new interpretations of existing knowledge can in a few seconds be distributed globally with the use of information technology and electronic communication. Knowledge is constantly changing or is becoming obsolete so rapidly that the distributors of knowledge - the teachers - can hardly be constantly updated. Knowledge is not static but dynamic and it moves at lightning speed in the information society. The very speed in which the amount of knowledge is increasing globally makes other demands on the teachers of today and of the future. Therefore it is necessary to revise the traditional understanding of the role of the teacher in the information society's education system [4].

The teaching of educational system in Romania - just like the other European systems - is facing some general requirements whose direction is imposed by the economic, social, political and cultural development, both on a national and international level. The Romanian National Curriculum has been devised taking into account the expectations that society has in these conditions from university and which university, in its turn, presents to the young generation during the educational and learning process [6].

These exigencies can be thus summarized:

- The aptitude for thinking critically and divergently which is likely to help the students make good use in different circumstances of the knowledge and skills they have acquired;

- The motivation and capacity to positively react to change, as a premise of personal development; 
- The aptitude for active social integration, combined with a set of personalized attitudes and values, that will enable the graduates to participate in the life of an open and democratic society.

For attaining the goals of Romanian educational system, a student-centred educational process has become a compulsory curricular orientation and consequently the application of certain teaching and learning strategies and of certain methods that should accomplish this aim has become equally impending [6].

Restructuring the initial training programs offered by the Universities, a central role in the Reform of the Romanian education is played by the continuous training of the teaching staff [2]. The two major directions in the restructuring of teacher training have been, during the last two years the decentralizing of the training offer and the increase in its quality.

The role of the teacher as organizer and distributor of the teaching has to be developed concurrently with the integration of ICT in the education programs, because as a parallel to the development there will be an increasing need to sort information and to process collected information to serviceable knowledge. In the future the teacher also has to be capable of acting as adviser and sparring partner for the students. This new interpretation of the traditional distribution of roles between teacher and students is necessary if the students are to take a greater responsibility for their own learning and have the opportunity of displaying greater independence in the learning process. For a long time this has been the case within tertiary education, where learning is the responsibility of the individual student, and the teachers are advisers.

A similar development can be expected within the other educational areas; however, the demand that university is also an important factor as a place of socialization for students still contributes to uphold many of the traditional teacher virtues as highly necessary. It may be more precise to talk about the extended role of the teachers than about their changing role.

The valuation of the scientific research activity has been materialized in the publication of books and papers in specialised reviews (in CNCSIS acknowledged publishing houses, papers published in CNCSIS acknowledged reviews, in ISI rated reviews, in the volumes of international conferences).

A synthesis of the results of the scientific research activity performed at the University Politehnica of Bucharest during 2007-2009 is presented in the chart below.

\begin{tabular}{|c|c|c|c|}
\hline Academic Year & 2007 & 2008 & 2009 \\
\hline Quantum Index & $\begin{array}{c}\text { Number } \\
\text { Value (lei) }\end{array}$ & $\begin{array}{c}\text { Number } \\
\text { Value (lei) }\end{array}$ & $\begin{array}{c}\text { Number } \\
\text { Value (lei) }\end{array}$ \\
\hline $\begin{array}{l}\text { Projects gained in international contests as } \\
\text { partner and coordinator }\end{array}$ & $\begin{array}{c}49 \\
-\end{array}$ & $\begin{array}{l}46 \\
-\end{array}$ & 36 \\
\hline $\begin{array}{l}\text { Grants obtained / developed through national } \\
\text { competitions }\end{array}$ & $\begin{array}{c}391 \\
\mathbf{1 1 0 . 7 1 9 . 2 0 8 , 2 5} \\
\end{array}$ & $\begin{array}{c}1152 \\
\mathbf{1 0 3 . 2 3 6 . 6 3 5 , 3 8}\end{array}$ & $\begin{array}{c}522 \\
33.379 .240,14\end{array}$ \\
\hline $\begin{array}{c}\text { Grants obtained / developed through } \\
\text { international competitions }\end{array}$ & $\begin{array}{c}41 \\
\mathbf{1 1 . 8 2 4 . 0 1 0}\end{array}$ & $\begin{array}{c}90 \\
11.642 .559\end{array}$ & $\begin{array}{c}51 \\
7.069 .981,66\end{array}$ \\
\hline $\begin{array}{c}\text { Projects / grants for research / advisory } \\
\text { services / technical and technological services } \\
\text { done / run directly with national and } \\
\text { international companies }\end{array}$ & $\begin{array}{c}51 \\
1.285 .590\end{array}$ & $\begin{array}{c}63 \\
1.626 .223,02\end{array}$ & $\begin{array}{c}54 \\
846.498,07\end{array}$ \\
\hline $\begin{array}{l}\text { Doctoral theses completed and presented } \\
\text { publicly }\end{array}$ & 191 & 181 & 211 \\
\hline $\begin{array}{c}\text { Papers, proceedings papers, reviews published } \\
\text { in ISI rated reviews }\end{array}$ & 323 & 566 & 450 \\
\hline $\begin{array}{l}\text { Papers published in foreign reviews from the } \\
\text { main stream, BDI indexed }\end{array}$ & 33 & 110 & 53 \\
\hline $\begin{array}{c}\text { Papers published in the volumes of ISI rated } \\
\text { international conferences and / or those } \\
\text { organized by international, professional } \\
\text { companies }\end{array}$ & 1028 & 1249 & 1422 \\
\hline $\begin{array}{c}\text { Papers published in CNCSIS acknowledged, } \\
\text { Romanian reviews - class B+ }\end{array}$ & 287 & 222 & 233 \\
\hline $\begin{array}{c}\text { Papers published in CNCSIS acknowledged, } \\
\text { Romanian reviews - class B }\end{array}$ & 31 & 86 & 79 \\
\hline $\begin{array}{l}\text { Books edited in CNCSIS acknowledged, } \\
\text { national publishing houses }\end{array}$ & 315 & 342 & 218 \\
\hline $\begin{array}{c}\text { Books published in prestigious international } \\
\text { publishing houses }\end{array}$ & 16 & 22 & 36 \\
\hline $\begin{array}{l}\text { Patents which belong to the university / } \\
\text { produces with intellectual ownership }\end{array}$ & 18 & 34 & 35 \\
\hline The overall number of teachers & 1592 & 1569 & 1545 \\
\hline The overall number of professors & 564 & 621 & 634 \\
\hline $\begin{array}{c}\text { The overall number of doctoral theses } \\
\text { supervisor }\end{array}$ & 258 & 273 & 288 \\
\hline
\end{tabular}


Like other groups in society, the teachers have to personally master the ICT-tools and their possibilities concurrently with the fact that ICT is used as an integrated part of the individual educations and subjects. In addition to this a massive effort within in-service training is to be implemented with the purpose of focusing on the pedagogical possibilities, which lies in the use of ICT, including the importance of ICT to the content, didactic and pedagogical principles of the subjects. In that way a fundament is created, which makes it possible for the teachers to use ICT both in the personal planning process and as an integrated element in the teaching and in the learning process [5].

This requires that the management is responsible for ensuring that the teachers have the qualifications, which are necessary for the teaching in question, but also that each individual teacher is responsible for keeping his or her general qualifications on a state of art level.

In this connection, it is necessary to look at the distribution of the teachers' working hours and find out if it is posing barriers to an effective ICT-integration. Areas of special priority could be:

- Ensuring that the general and basic ICTqualifications of the student teachers in the beginning of the course of study are brought to that sufficiently high basic level, which the education necessitates.

- Formulation of minimum requirements as to ICTqualifications, both general as well as subject related qualifications as a prerequisite for employment as a teacher.

- Formulation of requisite minimum requirements as to ICT-qualifications among the existing teacher groups. It is the aspiration that all teachers will be able to meet the minimum requirements at the end of the period.

The digital age is founded on respect for, and enjoyment of, cultural expression. New ICTs should stimulate multiculturalism and plurilingualism and enhance the capacity of the universities to develop activities to that end. As a confirmation of this concern, the United Nations Educational, Scientific and Culture Organization (UNESCO) is in the midst of defining a set of global ICT Competency Standards for Teachers (CST). The objectives of the project are to:

- Constitute a common set of guidelines that professional development providers can use to identify, develop or evaluate curriculum or teacher training programs in the use of ICT in teaching and learning;

- Provide a basic set of qualifications that allows teachers to integrate ICT into their teaching and learning, to advance student learning, and to improve other professional duties;

- Extend teachers' professional development to advance their skills in pedagogy, collaboration, leadership and innovative school development using ICT;

- Harmonize different views and vocabulary regarding the uses of ICT in teacher education.
Most university educators would agree that high-quality teaching and learning encompass a rich suite of activities: lectures, seminar discussions, library research, solitary study, formal and informal peer-to-peer discussion, faculty-student tutorials, and laboratories in the sciences and foreign languages. A live classroom presentation delivered by a poor lecturer may not be the best choice if a charismatic professor is lecturing over the Internet. A well-designed simulated lab may be an excellent substitute for a student who cannot attend a wet lab, or if the content of the lab can be more powerfully communicated as a simulation that allows visualization of complex microscopic processes. An online text chat may substitute for regular face-to face-meetings, but the quality of such interaction may be significantly magnified if students and faculty have an opportunity to meet in person occasionally. In foreign language instruction, learning may be enhanced by technological adjuncts to regular courses, such as online quizzes for drill and practice, real-time communication with native language speakers, and scaling the offering of seldomtaught languages to distributed populations.

\section{AN EXPERIMENT ON STUDENTS' QUALITY OF SOLVING PROBLEMS}

A study was performed to analyse some statistics concerning students' quality of solving problems in some Engineering courses in the University Politehnica of Bucharest.

For lack of space only one such experiment will be presented and some data are omitted.

A number of 24 students received a problem to be solved with the aid of a computer program. Their times of solving the problem are listed below:

\begin{tabular}{|l|l|l|l|l|l|l|l|}
\hline 3.48 & 3.30 & 3.51 & 3.49 & 3.60 & 3.26 & 3.28 & 3.53 \\
\hline 3.43 & 3.64 & 3.52 & 3.43 & 3.68 & 3.64 & 3.56 & 3.43 \\
\hline 3.37 & 3.48 & 3.46 & 3.57 & 3.48 & 3.60 & 3.48 & 3.53 \\
\hline
\end{tabular}

The mean is estimated by using the sample mean $\bar{x}=3.49$.

The variance is estimated by using the sample variance $s^{2}=\Sigma\left(x_{i}-\bar{x}\right)^{2} / 24=0.0122$.

The empirical distribution function is determined by $F_{24}\left(x_{i}\right)=i / 24, i \in\{1,2, \ldots, 24\}$.

The theoretical distribution function is $N\left(\mu, s^{2}\right)$;

$F\left(x_{i}\right)=\Phi\left(\frac{x_{i}-\bar{x}}{s}\right)$ (Laplace function).

Using these data, the value of the Kolmogorov-Smirnov statistics is $\mathrm{D}_{24}=\sup \left(\operatorname{abs}\left(F_{24}-F\right)\right)=0.09$.

From the chart of the Kolmogorov-Smirnov test one obtains for the first order error $0,01=P(D n>c) \Rightarrow c=0.35$.

Therefore the null hypothesis $\mathrm{H}_{0}$ is accepted and the selection data follow the normal distribution.

The confidence interval for the mean is determined by using the following statistics [8] 
$t=\frac{\bar{X}-\mu}{s} \sqrt{n}$ with $s^{2}=\frac{1}{n-1} \sum_{i=1}^{n}\left(x_{i}-\bar{x}\right)^{2}$

(where $n=24$. Then $0,95=P(A<\mu<B)$

implies $A=\bar{X}-\frac{s}{\sqrt{20}} * t_{0,975}^{(23)} \quad B=\bar{X}+\frac{s}{\sqrt{20}} * t_{0,975}^{(23)}$.

\section{CONCLUSIONS}

The modernization of Romanian education will become convincing when the reform materializes in the change of the didactic approach in class. This process of modernization will have to materialize in the formal curricular innovation (planning, syllabuses), elective textbooks, educational tools, the generalized access to the informational system and the new modalities of information that represent new quality supports in the coherent application of certain new didactic methods and strategies for which teachers need to be trained.

The information revolution has expanded networks and provided new opportunities for access to information [7]. It has also created new opportunities for generating and transferring information. Knowledge networks and sharing of information have expedited innovation and adaptation capacity. Changes in ICT have revolutionized the transmission of information. Semiconductors are getting faster, computer memories are expanding, and ICT prices are falling. Data transmission costs have fallen dramatically and continue to fall, bandwidth is growing, and Internet hosts are expanding and multiplying. Cellular phone usage is growing worldwide, adding to the pace of and capacity for change and innovation. As it is known, the economy rests on four pillars:

- A supportive economic and institutional regime to provide incentives for the efficient use of existing and new knowledge and the flourishing of entrepreneurship.

- An educated and skilled population to create, share, and use knowledge.

- A dynamic information infrastructure to facilitate the effective communication, dissemination, and processing of information.

- An efficient innovation system of firms, research centres, universities, consultants, and other organizations to tap into the growing stock of global knowledge, assimilate and adapt it to local needs, and create new technology.

These questions concern us all - students and professors alike. Several points must be borne in mind as one pursues these questions. First, ICT are only a part of a continuum of technologies, starting with chalk and books, all of which can support and enrich learning. Second, ICT, as any tools, must be considered as such, and used and adapted to serve educational goals. Third, many ethical and legal issues intervene in the widespread use of ICT in education, such as ownership of knowledge, the increasing exchange of education as a commodity, and globalization of education in relation to cultural diversity.
Innovations in information technology and telecommunications open unprecedented opportunities for learning to every person on the planet. But, as computers and new telecommunications dissolve the old limitations of time, distance, language, local competence and resources, every familiar model and practice in education the world over must be re-examined. From acquiring basic functional literacy to the most advanced search for new knowledge, every learning endeavor is being impacted by the new technologies.

\section{RFERENCES}

[1] Alberts, David S., Information Age Transformatio, Washington, DC, 2002. Available at http://www.dodecrp.org/files/Alberts_IAT.pdf.

[2] Government of Romania, Ministry of Education and Research, Romania's Contribution to the Debate on the Future 7th Research Framework Program of the European Union for 2007-2013

[3] Livingstone, S., and Bovill, M. - Young People and New Media, An LSEReport, 1999

[4] Polanyi, Michael - The Tacit Dimension, London :Routledge \& Kogan Paul, 1966

[5] Poole, Bernard John; Sky-McIlvain,Betsy; Jackson, Lorrie; Singer, Yvonne, Education for an Information Age. Teaching In The Computerized Classroom, 6th edition, 2006, published on-line and freely available at http://www.pitt.edu/ poole/InfoAge6frame.html

[6] Romania. Towards the European Higher Education Area. Bologna Process. National Reports $2004-2005$.

[7] Romania. Ministry of Education and Research. Higher Education in Romania - Progressing Towards the Bologna Objectives, 2006.

[8] Mariana Craiu, Laura Pânzar, Probabilităţi şi statistică, Ed. Printech, Bucureşti, 2005.

\section{Creative Commons Attribution License 4.0 (Attribution 4.0 International, CC BY 4.0)}

This article is published under the terms of the Creative Commons Attribution License 4.0 https://creativecommons.org/licenses/by/4.0/deed.en US 